\title{
A UTILIZAÇÃO DOS MEIOS ALTERNATIVOS A RESOLUÇÃO DE CONFLITOS NO FORNECIMENTO DE MEDICAMENTOS PELA ADMINISTRAÇÃO PÚBLICA BRASILEIRA
}

\author{
THE USE OF ALTERNATIVE DISPUTE RESOLUTION ON THE SUPPLY OF \\ MEDICINES BY THE BRAZILIAN PUBLIC ADMINISTRATION
}

\author{
${ }^{1}$ Raquel Nery Cardozo \\ ${ }^{2}$ Jose Carlos Cardozo
}

\section{RESUMO}

O presente trabalho visa demonstrar a importância da utilização dos meios alternativos de resolução dos conflitos relacionados à saúde que envolvam a administração pública em virtude do conflito entre a Reserva do Possível e o Mínimo Existencial, e da "Crise Estrutural do Poder Judiciário" orientada pela judicialização excessiva dos conflitos. Contribui ainda com o estudo de medidas capazes de assegurar o acesso a saúde pública sem que o jurisdicionado tenha que se submeter a demora nos julgamentos, contribuindo ainda na melhora da prestação da tutela jurisdicional.

Palavras-chave: Saúde, Meios, Alternativos, Resolução, Conflitos

\begin{abstract}
This study aims to demonstrate the importance of using alternative resolution of healthrelated conflicts means involving the public administration in connection with the conflict between reserve against possible and the minimum existential theory, and "Structural Crisis of the Judiciary" driven legalization excessive conflict. It also contributes to the study of measures to ensure access to public health without the claimants have to submit to delay the trials, further contributing to improve the provision of judicial protection.
\end{abstract}

Keywords: Health, Alternative, Dispute, Resolution, Conflicts

\footnotetext{
${ }^{1}$ Doutoranda em Sociologia e Direito pela Universidade Federal Fluminense - UFF, Niterói, Rio de Janeiro, (Brasil). Professora Assistente do quadro Permanente, da Universidade Federal Fluminense - UFF. E-mail: raquelncardozo@gmail.com

${ }^{2}$ Mestre em Direito pela Universidade Gama Filho - UGF, Rio de Janeiro, (Brasil). Professor Assistente, do Quadro Permanente da Universidade Federal Rural do Rio de Janeiro - UFRRJ, Seropédica, Rio de Janeiro. Email: cardozojosecarlos@gmail.com
} 


\section{INTRODUÇÃO}

O Poder Constituinte originário elencou um extensivo rol de direitos sociais fundamentais, englobando o direito a saúde, e determinando que o mesmo seja assegurado de forma universal pela administração pública brasileira, nos termos do artigo 196 da Constituição da República. Portanto, diante do principio da legalidade estrita, possui o administrador a obrigação de assegurar a todos esse direito fundamental.

Por outro lado, verifica-se a existência de uma "crise" na saúde pública em razão da impossibilidade do Estado-Administração conseguir assegurar este direito de forma ampla e irrestrita ante a escassez de recursos para assegurar este direito de forma universal, ensejando uma grande deficiência no fornecimento de medicamentos e de custeio de tratamentos médicos que são de alto custo e, portanto, muitas vezes negados pela via administrativa, não tendo conseguido chegar a um equilíbrio entre o Mínimo Existencial e a reserva do Possível.

Por conseguinte, a única forma de se obter este custeio é através da submissão do conflito a tutela jurisdicional, que também vem passando por uma crise estrutural por não estar conseguindo atender a todas as demandas em tempo hábil e de forma a satisfazer as necessidades do jurisdicionado, em razão de a judicialização excessiva das demandas relacionadas ao direito à saúde.

Portanto, o Judiciário, que era tido como o único meio capaz de conseguir assegurar este direito, não está conseguindo cumprir com este papel em razão da imensa quantidade de litígios e por não possuir uma estrutura técnica adequada para o julgamento rápido de tantas demandas.

Assim sendo, iniciou-se o estudo de meios para conseguir assegurar a tutela deste direito fundamental constitucional à saúde.

Neste aspecto o objetivo deste trabalho consiste em abordar a importância da adoção de meios alternativos de resolução de litígios relacionados ao Direito à Saúde para ajudar, talvez não na solução e eliminação do problema, mas sim na sua redução e com o escopo de tornar o direito à saúde acessível às pessoas, assegurando-lhes um direito constitucionalmente previsto, utilizando-se de pesquisa eminentemente bibliográfica e empírica, com visita a Câmara de Resolução de Litígios em Saúde no Rio de Janeiro. 


\title{
1. DIREITOS SOCIAIS FUNDAMENTAIS
}

\begin{abstract}
Nós, representantes do povo brasileiro, reunidos em Assembleia Nacional Constituinte para instituir um Estado Democrático, destinado a assegurar o exercício dos direitos sociais e individuais, a liberdade, a segurança, o bem-estar, o desenvolvimento, a igualdade e a justiça como valores supremos de uma sociedade fraterna, pluralista e sem preconceitos, fundada na harmonia social e comprometida, na ordem interna e internacional, com a solução pacífica das controvérsias, promulgamos, sob a proteção de Deus, a seguinte CONSTITUIÇÃO DA REPÚBLICA FEDERATIVA DO BRASIL ${ }^{1}$.
\end{abstract}

Estas são as palavras iniciais contidas na Constituição da República Brasileira que reconhece, já no seu preâmbulo, que para a instituição de um Estado Democrático faz-se necessário assegurar o exercício dos direitos sociais e individuais, entre outros direitos nela descritos.

Nada obstante o reconhecimento, pela Suprema Corte brasileira ${ }^{2}$ no sentido de que o preâmbulo da Constituição da República tem caráter meramente proclamatório, eis que revestida de significado doutrinário e impregnada de índole político-ideológica, é certo que o mesmo é utilizado como diretriz para a interpretação Constitucional, haja vista sintetizar o pensamento jurídico do legislador constituinte.

No mesmo acórdão, o Ministro Relator Celso de Melo afirma ainda que o preâmbulo apresenta-se destituído de normatividade e cogência, em razão dos elementos que compõem o seu conteúdo, sendo, portanto, mero vetor interpretativo do que se acha inscrito no "corpus" da Lei Fundamental.

Portanto, ainda que destituído de valor normativo, o preâmbulo, além de ser parte introdutória da Constituição da República, apresenta diretrizes para que a realização da hermenêutica constitucional seja realizada em consonância com o pensamento do legislador constituinte originário, devendo, portanto, ser amplamente respeitado.

Existem diversos textos normativos que determinam o dever de garantia dos direitos sociais, como o caso do artigo 16 da Declaração dos Direitos do Homem e do Cidadão, de 1789, que nada obstante não ser um texto vinculativo, e sem signatários, foi ratificado pela Assembleia Geral em 10 de dezembro de 1948.

\footnotetext{
${ }^{1}$ BRASIL. Constituição da República Federativa do Brasil. Brasília, DF: Senado Federal, 1988. Preâmbulo.

${ }^{2}$ BRASIL. Supremo Tribunal Federal. Medida Cautelar no Mandado de Segurança 24.645-DF. IMPTE.(S): Luiz Carlos Jorge Hauly E Outro IMPDO.(A/S): Mesa Da Câmara Dos Deputados. RELATOR: Min. Celso De Mello. DJ 15/09/2003. PP-00065.
} 
Outro dispositivo constitucional que trata dos Direitos Sociais, é o artigo $6^{\circ}$ da Constituição da República Brasileira ${ }^{3}$, parte integrante do seu Título segundo, que trata dos Direitos e Garantias Fundamentais.

Segundo Vicente de Paulo Barretto (BARRETO, 2010, p.193), estes são considerados valores supremos, ou seja, superior a todos os demais. Portanto, os Direitos sociais, aos quais se inclui o Direito à Saúde, em especial, por ser o foco deste trabalho, devem prevalecer em detrimento dos demais direitos, concepção esta decorrente do surgimento do Estado Social.

Nesta oportunidade convém mencionar que no Estado liberal, este anterior ao Estado Social, imperava a defesa da liberdade dos cidadãos. Os direitos prevalentes eram os civis e políticos. Havia um agir negativo, uma abstenção estatal. São os chamados direitos de primeira geração.

Já os direitos sociais, que surgiram no Estado Social de Direito, são considerados direitos de segunda geração, consoante as palavras de Manoel Gonçalves Ferreira Filho ao afirmar que os Direitos Sociais são apontados como a segunda geração dos direitos fundamentais, sendo direitos a prestações positivas por parte do Estado, vistos como necessários para o estabelecimento de condições mínimas de vida digna para todos os seres humanos. (FERREIRA FILHO, 2003, p. 310).

Segundo Norberto Bobbio (BOBBIO, 1992, p. 06)

os direitos sociais, por mais fundamentais que sejam, são direitos históricos, ou seja, nascidos em certas circunstancias, caracterizadas por lutas em defesa de novas liberdades contra velhos poderes, e nascidos de modo gradual, não todos de uma vez e nem de uma vez por todas.

Acrescente-se ainda que não só os direitos sociais, mas também o reconhecimento dos direitos humanos decorrem do contexto histórico em que a sociedade está inserida.

Além disso, nos dizeres de Eusébio Fernandez, os direitos humanos manifestam direitos variáveis e relativos a cada contexto histórico em que o homem se situe, ou seja, ele se modifica de acordo com o contexto social e o momento histórico pelos quais uma sociedade esteja passando. (FERNANDEZ, 1991, p. 100).

Voltando aos Direitos Sociais, Vicente de Paulo Barretto (BARRETO, 2010, p.211) escreve em sua obra que os Direitos Sociais foram considerados uma espécie de

\footnotetext{
${ }^{3}$ BRASIL. Constituição da República Federativa do Brasil. Brasília, DF: Senado Federal, 1988. Art. $6^{\circ}$ : São direitos sociais a educação, a saúde, a alimentação, o trabalho, a moradia, o lazer, a segurança, a previdência social, a proteção à maternidade e à infância, a assistência aos desamparados, na forma desta Constituição.
} 
instrumento político e jurídico que serviu à democratização do sistema econômico e social da sociedade liberal.

$\mathrm{Na}$ mesma oportunidade o doutrinador apresenta que o Estado Social de direito substituiu o Estado Liberal e ensejou o surgimento da ideia de igualdade material, em que o Estado se obriga a remover as injustiças encontradas na sociedade, com elaborações legislativas.

Saliente-se que Maria Celina Bodin de Moraes (MORAES, 2003, p. 86) diferencia a igualdade formal da substancial, sendo que a primeira consiste no direito a não receber um tratamento discriminatório. Só que segundo a jurista, nada obstante esta ser a forma básica da igualdade e estar expressamente prevista no artigo $5^{\circ}$, caput, ab initio, da Constituição da República, não é fácil promover esta igualdade, pois, as pessoas são diferentes em relação à classe econômica, religião, etc..

Já a igualdade substancial, desenvolvida por Aristóteles e trazida para o Direito pátrio por Rui Barbosa, consiste em tratar as pessoas, quando desiguais, em conformidade com a sua desigualdade.

Portanto, pelo que se verifica, os Direitos Sociais são considerados fundamentais e devem ser assegurados pelo Estado democrático de Direito.

\section{O CONFLITO ENTRE RESERVA DO POSSÍVEL E O MÍNIMO EXISTENCIAL E A EFETIVIDADE DO DIREITO SOCIAL FUNDAMENTAL À SAÚDE}

Foi mencionada anteriormente a fundamentalidade dos direitos sociais descritos na Constituição da República brasileira de 1988, dentre eles o direito a saúde, o qual é destaque no presente trabalho, e que é objeto de inúmeras demandas judiciais diante da crise que o sistema de saúde pública brasileira vem enfrentando em razão de não se conseguir chegar a um equilíbrio entre o Mínimo Existencial e a Reserva do Possível.

Ana Paula de Barcellos (BARCELLOS, 2002, p.272) afirma que

\footnotetext{
falar de eficácia positiva ou simétrica do mínimo existencial na área de saúde significa dizer que há um conjunto de prestações de saúde exigíveis diante do Judiciário por força e em conseqüência da Constituição. Mais que isso, tal afirmação significa que os poderes constituídos estão obrigados a colocar à disposição das pessoas tais prestações, seja qual for o plano de governo ou a orientação política do grupo que, a cada momento, estiver no poder.
} 
O Estado, latu sensu ${ }^{4}$, tem o dever de garantir e assegurar o acesso à saúde através do fornecimento de medicamentos ou do custeio de tratamentos médicos. Este é o papel do Estado Social.

Contudo, tem-se observado a inércia ou a negativa do Poder Público em garantir o acesso, da coletividade, ao direito à saúde, que como já visto anteriormente, é um direito fundamental constitucionalmente assegurado. Neste ponto, cabe ao Poder Judiciário assegurar os direitos supramencionados como uma garantia da manutenção do Estado Democrático de Direito, sem que com isso incorra na ofensa ao princípio da Separação dos Poderes por se tratar de um controle de legalidade.

Em verdade, o que se tem verificado é que a Administração sempre alega ter mais necessidades a atender do que recursos que dispõe e, por isso, tem que estabelecer prioridades. Daí tem-se a chamada "Reserva do Possível" que, contudo, não pode ser utilizada indiscriminadamente.

Entretanto, em contraposição à "Reserva do Possível”, existe o "Mínimo Existencial”, que abrange o necessário para que se tenha uma vida digna. Deverá ser feita uma ponderação dos interesses para solucionar conflitos da mesma hierarquia legal.

É importante salientar que a Administração tem a função de implementar políticas públicas e o Judiciário deve fazer um controle de legalidade dessa atuação Estatal, sendo certo que o não cumprimento injustificado do dever da administração em implementar estas políticas de governo enseja o controle judicial com a finalidade de promover a efetividade deste direito.

Segundo Luís Roberto Barroso (BARROSO, 2002, p. 85), a efetividade consiste na realização do Direito, no desempenho concreto da sua função social, representando a materialização, no mundo dos fatos, dos preceitos legais e simbolizando a aproximação entre o dever ser normativo e o ser da realidade social.

Acrescente-se ainda que para Hans Kelsen (KELSEN, 2006, p. 237), uma ordem jurídica é considerada válida quando as suas normas são, numa consideração global, eficazes, quer dizer, são de fato observadas e aplicadas.

Portanto, não basta que haja uma previsão legal. Se o constituinte originário optou por um sistema universal de direito a saúde, o enquadrou como um direito social

\footnotetext{
${ }^{4}$ BRASIL. Constituição da República Federativa do Brasil. Brasília, DF: Senado Federal, 1988. Art. 23: É competência comum da União, dos Estados, do Distrito Federal e dos Municípios:

II - cuidar da saúde e assistência pública, da proteção e garantia das pessoas portadoras de deficiência;
} 
fundamental e preceitua o principio da legalidade estrita destinada ao administrador público, a sociedade tem que ter este direito efetivado de alguma forma, ainda que através da tutela jurisdicional que, contudo, em muitos casos tem se mostrado como único meio de se conseguir efetivar este direito. De nada adianta a existência de uma norma que assegure um direito sem que tenha real efetividade na sua aplicação.

Por outro lado, é evidente a dificuldade do poder público em assegurar o acesso universal a saúde, fazendo com que se busque a tutela jurisdicional para assegurar este direito, o que enseja a denominada judicialização das politicas públicas de saúde, que quando excessiva, ocasiona a crise estrutural do Poder Judiciário, fenômenos que serão melhor estudados a seguir.

\section{A JUDICIALIZAÇÃO DAS POLITICAS PÚBLICAS DE SAÚDE}

Frente a necessidade de garantir o direito social fundamental à saúde, a judicialização vem ganhando espaço tendo em vista, a impossibilidade do Estado em assegurar este direito, como apresentado anteriormente.

Existem, dentro do tema escolhido, diversas hipóteses comuns de acontecer em relação à recusa do fornecimento de medicamento ou custeio de tratamentos pelo Poder Público, como no caso do custeio do tratamento de doenças que causam risco de vida e a pessoa que não dispõe de recursos em sendo portadora de hepatite $C^{5}$, em que o tratamento é custoso e o requerente acaba por não ter o tratamento adequado por este não ter recursos financeiros e em razão da recusa do Estado a custear o seu tratamento.

Nestes casos, não haverá outro meio para o pretendente, que não seja através do Poder Judiciário, para poder ter garantido o seu tratamento.

É importante mencionar ainda que, atualmente, a questão levantada está se direcionando para o posicionamento de que o direito coletivo a saúde é um direito fundamental e, por isso, deve ser assegurado pela Administração Pública e viabilizado pelos operadores do Direito, como forma de manutenção do Estado democrático de direito.

A jurisprudência tem se direcionado no sentido de possibilitar o recurso ao Judiciário para poder obter tanto os medicamentos quanto os tratamentos das enfermidades.

\footnotetext{
${ }^{5}$ BRASIL. Superior Tribunal de Justiça, Recurso Especial 992811 / SP. Min. Relator: Luiz Fux. Órgão Julgador: Primeira Turma. Data do Julgamento: 18.nov.2008. Data da Publicação / fonte: DJe 15.dez.2008. Disponível em http://www.stj.jus.br.
} 
Por conseguinte, devem ser verificadas as políticas públicas já existentes e a sua efetividade na proteção ao direito da saúde coletiva, sem deixar de tratar das desigualdades sociais existentes que acabam por excluir aqueles que pertencem às classes mais baixas e desinformadas.

Não menos importante é a questão atinente ao manejo dos instrumentos processuais existentes no Brasil e a do efeito da coisa julgada nas decisões no que diz respeito às ações individuais, como forma de garantir o direito à igualdade às pessoas que não possuam condições de custear o tratamento.

Trata-se de um direito coletivo, saúde, que acaba por ser assegurado somente àqueles que tenham o acesso às informações que possibilitem o seu acesso à justiça. Muitas pessoas não sabem nem da existência da Defensoria Pública, que é uma instituição relativamente recente no ordenamento jurídico brasileiro e que, portanto, acabam sendo tolhidas do exercício do direito à saúde.

Ainda com a ausência de informações à determinados grupos sociais a respeito dos seus direitos, é inegável que, por outro lado, esteja havendo um movimento no sentido de busca pela efetivação dos direitos fundamentais por parte daqueles que os tenha sido violados.

Por conseguinte, tem havido uma crescente procura pela tutela jurisdicional favorável, ensejando um ativismo judicial, especialmente, em relação às políticas públicas de saúde.

Destarte, é de extrema importância estudar este aumento do número de demandas judiciais, o exercício desta atividade jurisdicional, que acaba sendo a única forma de assegurar a efetivação do direito fundamental à saúde reprodutiva, bem como o posicionamento que tem sido adotado por alguns Tribunais de Justiça brasileiros.

Contudo, o grande aumento no número de ajuizamento de demandas tem gerado efeitos colaterais, dentre eles, a falta de mão-de-obra qualificada para apreciar as demandas judiciais e decisões que desagradam a ambas as partes que acabam, de certa forma, sendo sucumbentes, ocasionando a denominada Crise Estrutural do Poder Judiciário, como se verá a seguir.

\section{A CRISE ESTRUTURAL DO PODER JUDICIÁRIO}

A cada dia são ajuizadas inúmeras ações judiciais para que o Estado Juiz aprecie pedidos e profira decisões, as quais nem sempre atendem à pretensão dos jurisdicionados e, 
não raro, até mesmo contrariam os interesses de ambas as partes, o que gera uma sensação de insegurança a respeito do deslinde do conflito em apreço.

$\mathrm{O}$ aumento do número de conflitos, pode ser atribuído ao avanço das inovações tecnológicas e comerciais decorrentes da globalização, que grassou como consequência da evolução das comunicações aliada ao forte desenvolvimento tecnológico, gerando reflexos também nas relações sociais.

Paralelamente, percebe-se a existência de uma política, por parte dos tribunais de justiça, em avocar a tomada de decisões quando se está diante de um conflito e a cultura de ter que submete-los a apreciação judicial também contribui sobremaneira para a judicialização excessiva que tem sido verificada nos tribunais brasileiros, principalmente no caso de fornecimento de medicamentos pela administração pública haja vista a universalidade do direito social fundamental a saúde assegurado pela Constituição da República Brasileira nos seus artigos $6^{\circ 6}$ e $196^{7}$.

Tendo em vista esta avocação de julgamento dos conflitos pelos Tribunais de Justiça brasileiros, pode-se questionar o motivo ensejador uma vez que isso tem gerado um problema de aumento significativo de demandas frente a um número reduzido de mão-de-obra qualificada para movimentar esta máquina judiciária.

Verifica-se uma expansão dos poderes dos tribunais brasileiros como uma forma de ampliação da função do Estado nas sociedades complexas, e também na solução das disputas que surgem entre os atores sociais e instituições políticas (LIJPHART e WAISMAN, 1996; GUARNIERI e PEDERZOLI, 2001).

Portanto, este poderia ser um fator que contribui para este tipo de movimento.

Michael W. McCann afirma que o fato de o tribunal ser um influenciador de estratégias políticas, gerando o seu fortalecimento, pode se dar de cinco formas, quais sejam, o deslocamento do conflito, catalisando ordens judiciais, oportunidades e recursos, encorajando novas disputas e iniciativas, criando um constrangimento estratégico sobre as escolhas das partes envolvidas e ainda incentivando a contramobilização. (MCCANN, 2010, 186-188).

\footnotetext{
${ }^{6}$ BRASIL. Constituição da República Federativa do Brasil. Brasília, DF: Senado Federal, 1988. Art. $6^{\text {o: }}$ São direitos sociais a educação, a saúde, a alimentação, o trabalho, a moradia, o lazer, a segurança, a previdência social, a proteção à maternidade e à infância, a assistência aos desamparados, na forma desta Constituição.

${ }^{7}$ BRASIL. Constituição da República Federativa do Brasil. Brasília, DF: Senado Federal, 1988. Art. 196: A saúde é direito de todos e dever do Estado, garantido mediante políticas sociais e econômicas que visem à redução do risco de doença e de outros agravos e ao acesso universal e igualitário às ações e serviços para sua promoção, proteção e recuperação.
} 
Segundo o doutrinador, o deslocamento do conflito ocorre quando os atores sociais preferem submeter ao judiciário questões que envolvem os seus conflitos que envolvam questões divididas e vulneráveis para tentar solucionar, ocorrendo, portanto, uma certa proteção das elites.

No que diz respeito ao tribunal como catalisador de ordens judiciais, oportunidades e recursos, estimulando respostas positivas dos atores governamentais ou grupos de cidadãos não diretamente envolvidos nos casos, quando o tribunal atua em uma disputa ele pode fazer com que seja aumentado o grau de relevância da questão na agenda pública, privilegiando o interesse de determinada parte naquela demanda.

Em relação ao encorajamento de novas disputas e iniciativas de mobilização estratégica, o doutrinador afirma que

A influência judicial vai além de apenas encorajar novas disputas e iniciativas de mobilização estratégica. Além disso, os tribunais frequentemente influenciam as posições estratégicas das partes já engajadas em negociações políticas ou lutas relacionais em curso. Como tal, os "precedentes" judiciais discutidos anteriormente podem influenciar de modo significativo no aumento relativo de poder das diversas partes presas em conflitos prolongados. (MCCANN, 2010, 186)

A quarta forma pela qual o tribunal influencia as estratégias políticas se dá pela criação de um constrangimento estratégico sobre as escolhas das partes envolvidas, já que da mesma forma que os tribunais instituem oportunidades e recursos, criam constrangimentos e desincentivos, o que acaba beneficiando uma das partes.

No que tange ao incentivo da contramobilização, McCann afirma que as decisões dos tribunais geram precedentes que podem desencadear reações dos movimentos populares que venham a trabalhar no sentido de desfazer o que ele denomina de "erros judiciais", o que pode ser considerado uma falha no cumprimento das decisões, mas também um sinal de poder no que diz respeito ao impacto das decisões nos movimentos sociais.

Todo este processo tem por consequencia o ajuizamento de uma infinidade de ações judiciais, assoberbando cada vez mais os julgadores, que quase não conseguem dar conta de decidi-las com a celeridade e a qualidade que os jurisdicionados esperam e merecem, fatores estes de grande contribuição para a denominada Crise Estrutural do Poder Judiciário.

A necessidade de recorrer ao julgador Estatal para decidir todo e qualquer tipo de conflito pode ensejar a, acima mencionada, judicialização que, quando excessiva, ofende ao Principio da Separação dos Poderes, uma vez que haveria uma interferência da atuação do 
Juiz nas outras esferas - Executiva e Legislativa, além de nem sempre assegurar um julgamento justo e em tempo razoável.

Ocorre que a judicialização, passou a ser vista como uma forma segura de garantir a efetivação dos direitos, denotando alguns aspectos negativos, como os mencionados anteriormente, ocasionando um grande volume no surgimento das demandas e, consequentemente, demora nas decisões judiciais e piora na sua qualidade em decorrência da excessiva quantidade de processos atribuídos aos profissionais especializados. Além disso, os gastos com processos e a demora dos mesmos também são grandes. ${ }^{8}$

Boaventura afirma que houve, a transferência da legitimidade dos poderes legislativo e executivo para o judiciário, e este fato também é um dos propulsores o que enseja excessiva expectativa, que por sua vez ocasiona grande frustração quando não atendida, culminando com a "Crise Estrutural do Poder Judiciário", levando à descrença na aplicação do direito e dificultando a existência de uma sociedade democrática. (SANTOS, 2007, p. 10 19).

Percebe-se que esta "Crise" decorre da incapacidade do sistema judicial em desempenhar as suas funções típicas em um Estado Democrático de Direito.

Para o autor, este fenômeno se apresenta como um marco motivador para a adoção de meios alternativos de solução de conflitos.

Desta forma a Crise Estrutural do Poder Judiciário, foi um importante fator que teve grande contribuição para o estudo, e necessidade de adoção, de meios alternativos para a resolução dos conflitos, no caso do presente estudo, os que envolvam a dicotomia direito social universal a saúde e a escassez de recursos financeiros da administração pública para fornecer os medicamentos necessários ao tratamento de enfermidades, como se verá a seguir.

\section{DA IMPORTÂNCIA DA UTILIZAÇÃO DE MEIOS ALTERNATIVOS DE RESOLUÇÃO DE CONFLITOS NO FORNECIMENTO DE MEDICAMENTOS PELA ADMINISTRAÇÃO PÚBLICA BRASILEIRA}

\footnotetext{
${ }^{8}$ Segundo o CNJ (Conselho Nacional de Justiça), a despesa total do Poder Judiciário cresceu 7,2\% em 2012 e chegou a $R \$ 57,2$ bilhões. O valor equivale a 1,3\% do produto interno bruto (PIB) nacional e a 3,2\% do montante gasto pela União e pelos estados e municípios no ano. Os gastos com recursos humanos consumiram $R \$ 50,75$ bilhões, ou $88,7 \%$ do orçamento, mas esse percentual vem diminuindo nos últimos anos. Os dados fazem parte do Relatório Justiça em Números 2013, divulgado nesta terça-feira (15/10), em Brasília/DF. Disponível em http://www.cnj.jus.br/noticias. Acesso em 05.jan.14.
} 
Tendo em vista a excessiva judicialização dos conflitos, conforme acima mencionado e a consequente crise estrutural do Poder Judiciário, iniciou-se uma busca por meios alternativos de resolução de conflitos que possam ser capazes de assegurar a efetivação do direito a saúde.

Segundo Medina (MEDINA, 2004, p. 18 - 19), a nomenclatura ADR (Alternative Dispute Resolution) surgiu por volta da década de sessenta do século passado nos Estados Unidos, sendo, portanto, relativamente nova, mas o registro de utilização de seus métodos são muito antigos. Tem-se notícia, apenas a título de exemplo, de registros de uso da arbitragem por volta de 3.000 a.C. na Babilônia.

Geralmente, quando se fala em meios alternativos de resolução de conflitos, se tem em mente a mediação ${ }^{9}$, a conciliação ${ }^{10}$ e a arbitragem ${ }^{11}$.

Verifica-se, contudo, que por mais que a conciliação seja uma forma eficiente e rápida de resolver um litígio, quando feita da forma correta, ainda não lhe foi dada a devida importância, seja em decorrência da cultura que a maioria das pessoas possui no sentido de ser necessária uma decisão judicial para resolver o litígio, seja pela forma como a mesma é feita, que em regra, é muito rápida existindo um despreparo dos Conciliadores, ou até mesmo pela ausência de profissionalização desta importante função.

A Conciliação tem sido amplamente utilizada nos Tribunais brasileiros e, prevista em $\operatorname{lei}^{12}$. O Conselho Nacional de Justiça tem incentivado sobremaneira a realização de audiências de conciliação através da Semana Nacional de Conciliação, mas fora deste tipo de evento ainda não se obtém muito êxito na grande maioria dos litígios, que pode decorrer de uma cultura de ineficiência, o que gera descrença no uso do procedimento.

No que diz respeito a arbitragem ${ }^{13}$, por ser aplicada nas relações em que as partes sejam capazes de contratar e que envolvam direitos disponíveis, nota-se que se distancia dos conflitos instaurados no âmbito da saúde.

A mediação, que já era conhecida desde a Grécia antiga, na China e usada também na Civilização Romana, apenas recentemente vem se tornando cada vez mais usada,

\footnotetext{
${ }^{9}$ A Mediação é regulamentada pela Lei 13.140 de 26 de junho de 2015 e pelo Código de Processo Civil em vigor.

${ }^{10}$ A conciliação é prevista nos artigos 277, 331, 448 e 740 da LEI 5869 de 11 de janeiro de 1973 e no artigo $2^{\circ}$ da Lei 9099 de 26 de setembro de 1995, dentre outros dispositivos legais.

${ }^{11}$ BRASIL. LEI No 9.307 de 23 de setembro de 1996.

${ }^{12}$ A conciliação é prevista nos artigos 277, 331, 448 e 740 da LEI 5869 de 11 de janeiro de 1973 e no artigo $2^{\circ}$ da Lei 9099 de 26 de setembro de 1995, dentre outros dispositivos legais.

${ }^{13}$ BRASIL. LEI No 9.307 de 23 de setembro de 1996.
} 
especialmente em certos países que vêem se beneficiando e se especializando nas últimas décadas, ${ }^{14}$ ganhando destaque na década de 1980, nos Estados Unidos. ${ }^{15}$

Segundo Moore (MOORE, 1998, p. 32), as culturas judaicas, cristãs, islâmicas, hinduístas, budistas, confucionistas e diversas culturas indígenas possuem em seu histórico a prática da mediação, sendo que já nos tempos bíblicos, as lideranças religiosas e políticas das comunidades judaicas utilizavam da mediação como forma de dirimir conflitos, o que também foi adotado pelas comunidades cristãs emergentes que entendiam Jesus Cristo como mediador entre Deus e os homens.

No mesmo momento o autor afirma ainda que este papel de mediador foi assumido pelo clero, o que tornou as Igrejas Católica, na Europa Ocidental, e Ortodoxa, no leste Mediterrâneo, as principais organizações de mediação e gerência dos conflitos no mundo ocidental.

Segundo Luciane Moessa na mediação a resolução do conflito é construída pelas partes, as quais não estão limitadas apenas aos critérios legais, mas também a outros parâmetros importantes para que as partes envolvidas possam chegar a um acordo por elas construído. (SOUZA, 2010, p.130), o que, contudo, merece aprofundamento no estudo e regulamentação legal para eventual uso no caso do fornecimento de medicamentos e/ou tratamentos almejados pelos jurisdicionados.

A Lei 13.140 de 2015, além de regulamentar a mediação entre particulares como meio de solução de controvérsias, também dispõe sobre a autocomposição de conflitos no âmbito da administração pública.

Assim, parece que o legislador direcionou, preferencialmente, a mediação para os conflitos que envolvam particulares, e a autocomposição para os conflitos no âmbito da administração pública, realizando ainda uma separação geográfica, ou seja, enquanto a mediação é tratada no capítulo 1 da lei (artigos $2^{\circ}$ ao 31 ), a autocomposição de conflitos em que for parte pessoa jurídica de direito público é abordada no capitulo 2 (artigos 32 a 40),

\footnotetext{
${ }^{14}$ Centro Brasileiro de Mediação. Disponível em http://www.centrobrasileirodemediacao.com.br. Acesso em 12.nov.2013.

${ }^{15}$ Quanto ao momento do surgimento da mediação, diferentemente do apontado pelo Centro Brasileiro de mediação, Laura Garcia Raga (Escuelas de Mediación In J. Henri B. Peris e Francisco H. Mena (directores), Mediación Familiar, Madrid: Dykinson, 2010, Tomo III, p. 110), afirma que as técnicas de mediação começaram a ser utilizadas como forma pacifica de resolução de conflitos entre patrões e empregados nos Estados Unidos, já na década de trinta, tendo sido criado o Serviço Federal de Conciliação e Mediação em 1947. Ao final dos anos de 1960 e princípios de 1970 que lhes foram dados contornos pacifistas em relação aos problemas de violência ocorridos na sociedade norte americana.
} 
nada obstante no artigo 33 o legislador se referir a criação de Câmaras de Mediação para os casos de prevenção e resolução de conflitos no âmbito da administração pública. ${ }^{16}$

Portanto, nos casos do Direito à Saúde, o meio alternativo mais adequado a solucionar o conflito deve se dar através da autocomposição, nos termos da lei 13.140 de 2015, sem, contudo, excluir a possibilidade de utilização de outros meios neste caso.

Ressalte-se que segundo o processualista Fredie Didier Jr (DIDIER, 2015, p. 68), os meios de solução dos conflitos varia de acordo com a titularidade do poder de decidir o conflito, que pode ser das partes, autonomia, ou de terceiro, heteronomia.

Às formas de solução de conflito em que não haveria o exercício da jurisdição estatal, o doutrinador denomina de equivalentes jurisdicionais, que pode se dar através da autotutela, autocomposição, mediação ${ }^{17}$ e arbitragem.

No presente trabalho, diante do fato de o legislador tratar na Lei 13.140 de 2015 da autocomposição nos casos dos litígios envolvendo a administração pública, faz-se importante mencionar que neste tipo de equivalente jurisdicional, existe o consentimento espontâneo de pelo menos um dos envolvidos no conflito em favor do interesse alheio, podendo se dar de três formas, quais sejam, a transação, com concessões mútuas, a submissão, quando existe o reconhecimento da procedência do pedido, e a renúncia da pretensão deduzida. (DIDIER, 2015, p. 69).

Outra norma legal que aborda os meios alternativos de resolução de conflitos que envolvam a administração pública é o Código de Processo Civil vigente, Lei 13.105 de março de 2015, que já no artigo $3^{\circ}$ trata do tema, aprofundando-o no seu artigo 174.

No caso do CPC, o legislador já menciona neste artigo 174, caput e incisos, que é competência de todos os entes federativos, União, os Estados, o Distrito Federal e os Municípios, criar as câmaras de Mediação e Conciliação com atribuição para resolução de conflitos envolvendo órgãos e entidades da administração pública. ${ }^{18}$

\footnotetext{
${ }^{16}$ Neste aspecto parece que houve uma certa "confusão" na nomenclatura utilizada pelo legislador. Enquanto no caput do artigo 32 da Lei 13.140 de 2015 o legislador menciona "câmaras de prevenção e resolução administrativa de conflitos, no âmbito dos respectivos órgãos da Advocacia Pública, diferenciando ainda no artigo $1^{\circ}$ a mediação, como meio de solução de controvérsias entre particulares, da autocomposição de conflitos, como meio a ser utilizado no âmbito da administração pública, no artigo 33, autoriza a aplicação subsidiária do procedimento de mediação (Subseção I da Seção III do Capítulo I da Lei 13.140/15) enquanto não forem criadas as câmaras de mediação, discussãoo essa que merece aprofundamento em trabalho próprio.

${ }^{17}$ Ressalte-se que a mediação pode se dar em ambito extrajudicial ou judicial, sendo que neste último caso passou a ser obrigatória e é tratada como uma fase do processo civil conforme determinação do artigo 334 do Código de Processo Civil.

${ }^{18} \mathrm{O}$ melhor entendimento deve ser no sentido de se tartar de competência concorrente diante da possibilidade de disposição do mesmo assunto pelos entes federativos, com a primazia da União para a
} 
Verifica-se que neste dispositivo legal o legislador menciona, novamente, as câmaras de mediação e conciliação para dirimir os conflitos envolvendo os órgãos e entidades da administração pública.

Neste aspecto é importante fazer uma breve análise a respeito do conceito de mediação para demonstrar que se difere da autotutela.

Warrat, que entende que a mediação é

uma forma ecológica de resolução dos conflitos sociais e jurídicos; uma forma na qual o intuito de satisfação do desejo substitui a aplicação coercitiva e terceirizada de uma sanção legal. A mediação é uma forma alternativa (com o outro) de resolução de conflitos jurídicos, sem que exista a preocupação de dividir a justiça ou de ajustar o acordo às disposições do direito positivo.(Warrat, 1988, p. 102)

Por este conceito, o que importa é a resolução do conflito, sem que o acordo tenha que se ajustar às disposições do direito positivo, ou seja, parece que pode ser feito um acordo que não tenha amparo legal, mas que possa resolver o conflito instaurado, o que não pode ocorrer no âmbito da administração pública eis que deve ser respeitado o principio da legalidade e da indisponibilidade do bem público.

Feita esta breve abordagem, passa-se a exposição de uma experiência já iniciada no município do Rio de Janeiro, e que tem se mostrado bastante eficaz na resolução dos litígios de saúde na Cidade carioca. Trata-se da Câmara de Resolução de Litígios de Saúde, que tem por finalidade promover o atendimento de partes assistidas pela Defensoria Pública do Estado e pela Defensoria Pública da União, que demandem prestação de serviço de saúde do SUS, de modo a buscar solução administrativa para os pedidos e evitar o ajuizamento de ações.

Esta Câmara reúne a Procuradoria Geral do Estado, a Procuradoria Geral do Município, o Tribunal de Justiça do Estado, a Defensoria Pública do Estado, a Defensoria Pública da União, a Secretaria de Estado de Saúde e a Secretaria Municipal de Saúde na tentativa de buscar uma alternativa terapêutica padronizada pelo SUS no caso de o medicamento solicitado não estar inserido naquela lista.

Percebe-se que não se trata de uma câmara de mediação como proposto pelo legislador ordinário, mas sim de uma câmara de resolução de litígios de saúde, conforme se propõe este trabalho como forma de melhor assegurar a eficácia do direito fundamental social

de normas gerais, nos termos do artigo 24, parágrafo $1^{\circ}$, CRFB, acrescentando ainda que a presente material se enquadra no artigo 24 , XI, do mesmo diploma constitucional. 
a saúde sem ter que submeter o conflito a tutela jurisdicional e assoberbar ainda mais o Poder Judiciário de demandas que podem ser resolvida.

Portanto, em muitos casos, o litígio deixa de ser judicializado e o paciente tem sua demanda satisfeita de forma rápida e eficaz se comparado com o tempo que o processo judicial levaria para determinar, ou não, o fornecimento do medicamento ou tratamento pelo Estado, latu sensu, devendo ser dada maior atenção a este tipo de estudo que objetiva promover o direito a saúde constitucionalmente assegurado.

\section{CONSIDERAÇÕES FINAIS}

Diante do acima exposto, pode-se verificar que existe uma grande dificuldade do administrador público, e também do Judiciário, em assegurar o acesso a medicamentos e tratamentos médicos que garantam o direito social fundamental a saúde.

Verifica-se que a previsão constitucional de garantia universal e a ausência de recursos públicos ensejam uma deficiência no fornecimento e custeio voluntário de medicamentos e tratamentos médicos, fazendo com que pessoas permaneçam enfermas e recorram ao Poder Judiciário na tentativa de conseguir determinado medicamento ou tratamento e ensejando a discussão entre a reserva do possível e o mínimo existencial.

O fato de haver uma crescente demanda por fornecimento de medicamentos através da via judicial contribui sobremaneira para a judicialização excessiva, ensejando a crise estrutural do Poder Judiciário, acarretando demora nas decisões em decorrência do excesso de demandas ajuizadas frente a insuficiente mão-de-obra qualificada para dar andamento as ações com pedido de fornecimento de medicamentos ou custeio de tratamentos que sejam essenciais a garantia do direito social fundamental a saúde.

Este trabalho, que faz parte do estudo inicial de tese de doutoramento, busca sugerir o incremento e ampliação na adoção dos meios alternativos de resolução de conflitos, como as Câmaras de Resolução de Litígios de Saúde, já existentes em alguns municípios brasileiros, como no Rio de Janeiro, na tentativa de reduzir demandas judiciais e garantir o direito a saúde das pessoas. 


\section{REFERÊNCIAS:}

BARCELlOS, Ana Paula de. A Eficácia Jurídica dos Princípios Constitucionais. O Principio da Dignidade da Pessoa Humana. Rio de Janeiro: Renovar, 2002.

BARRETO, Vicente de Paulo. O Fetiche dos Direitos Humanos e outros temas. Rio de Janeiro: Lúmen Júris Editora, 2010.

BARROSO, Luis Roberto. O Direito Constitucional e a Efetividade de suas Normas. Rio de Janeiro: Renovar, 2002. $6^{\circ} \mathrm{Ed}$.

BOBBIO, Norberto. A Era do Direitos. Trad. Carlos Nelson Coutinho. Rio de Janeiro: Ed. Campus, 1992.

BRASIL. Constituição da República Federativa do Brasil. Diário Oficial da União, Brasília, data da publicação: 05 de outubro de 1988.

BRASIL. Decreto 1637. Lei dos Sindicatos profissionais e Sociedades Cooperativas. Diário Oficial da União, Brasília, data da publicação 05 de janeiro de 1907.

BRASIL. Lei 5869. Código de Processo Civil. Diário Oficial da União, Brasília, data da publicação 11 de janeiro de 1973.

BRASIL. Lei 9099. Lei dos Juizados Especiais Cíveis. Diário Oficial da União, Brasília, data da publicação 11 de janeiro de 1973.

CENTRO BRASILEIRO DE MEDIAÇÃO. Disponível em http://www.centrobrasileirodemediacao.com.br/umpou.html. Acesso em 12.nov.2013.

CONSELHO NACIONAL DE JUSTIÇA. CNJ. Disponível em http://www.cnj.jus.br. Acesso em 05.jan.14.

DIDIER JR., Fredie. Curso de direito processual civil: introdução ao direito processual civil, parte geral e processo de conhecimento. 17. ed. v.1. Salvador: Ed. Jus Podivm, 2015.

FERNANDEZ, Eusébio. Teoria de La justicia y derechos humanos. Madrid: Editorial Debate, 1991.

FERREIRA FILHO, Manoel Gonçalves. Curso de Direito Constitucional, São Paulo: Saraiva,Ed., 30 ed., 2003.

FISHER, Roger. URY, Willian. PATTON, Bruce. Como chegar ao sim? Vera Ribeiro e Ana Luiza Borges (trad.). Rio de Janeiro: Imago Ed., 2005.

GARCÍA RAGA, Laura. Escuelas de Mediación. In: J. Henri B. Peris e Francisco H. Mena (directores), Mediación Familiar, Madrid: Dykinson, 2010, Tomo III.

GUARNIERI, C.; PEDERZOLI, P. The Power of Judges. Oxford University, 2001. 
GUSTIN, Miracy Barbosa de Sousa. Os Fundamentos Teóricos de um Programa de Mediação. Palestra, Departamento de Direito da UFOP, 2009. In SURLO, Gerlis Prata; DIAS, Maria Tereza Fonseca. Mediação e cidadania nos núcleos de prática jurídica: a experiência da Universidade Federal de Ouro Preto. Trabalho publicado nos Anais do XIX Encontro Nacional do CONPEDI realizado em Fortaleza - CE nos dias 09, 10, 11 e 12 de Junho de 2010. Disponível em www.conpedi.org.br. Acesso em 10.set.2013.

HARVARD Disponível em http://www.pon.harvard.edu. Acesso em 10.jan.2014.

JARES, X. R. Educación y conflicto. Guia de educación para La convivência. Editorial Popular, Madrid: 2001.

KELSEN, Hans. Teoria Pura do Direito. Trad. João Baptista Machado. São Paulo: Martins Fontes, 2006.

LIJPHART, A., WAISMAN, C. H. (Ed.). Institutional Design in New Democracies. Boulder: Westview, 1996.

MARTÍN, Nuria Belloso. A Mediação: a melhor resposta ao conflito? In Fabiana Spengler e Douglas Luca (org.), Justiça Restaurativa e Mediação, Ijuí: Ed. Unijuí, 2011, p. 324.

MEDINA, Eduardo Borges de Mattos. Meios alternativos de solução de conflitos: o cidadão na administração da justiça. Porto Alegre: Sérgio Antonio Fabris, 2004.

MEJÍAS GÓMEZ, J. F.: Resolución alternativa de conflictos. Curso sobre resolución alternativa de conflictos (Arbitraje, conciliación). Valencia: Generalit Valenciana - Conselleria de Bienestar Social, 1998.

MCCANN, Michael W. (2010). "Poder judiciário e mobilização do direito: uma perspectiva dos 'usuários"'. Revista da EMARF, Cadernos Temáticos - Justiça constitucional no Brasil: política e direito, Rio de Janeiro: EMARF - TRF 2a Região. Disponível em: http://www.trf2.gov.br/emarf/documents/revistaemarfseminario.pdf\#page=176, acesso em: 10.07.2014.

MOORE, Christopher W. O Processo de Mediação: Estratégias Práticas para a Resolução de Conflitos. 2. ed. Porto Alegre: Artmed, 1998.

MORAES, Maria Celina Bodin de. Danos à pessoa humana. Uma leitura civil constitucional dos Danos Morais. Rio de Janeiro: Renovar, 2003.

RAMOS FILHO, Wilson. A conciliação como obsessão do capialismo descomplexado. In : Luiz Günther e Rosemerie Pimpão. Conciliação: Um caminho para a paz social, Curitiba: Juruá, 2013.

SANTOS, Boaventura de Sousa. Para uma Revolução Democrática da Justiça. São Paulo: Cortez, 2007.

SENADO FEDERAL. Disponível em http://legis.senado.gov.br. Acesso em 10.jan.14. 
SHAPIRO, Ronald M., The Power of Nice-How to Negociate So Everyone Wins-Especially You!. Ed. John Wiley \& Sons, Inc., 2001.

SOUZA, Luciane Moessa de. Meios consensuais de solução de conflitos envolvendo entes públicos e a mediação de conflitos coletivos. Tese de doutoramento em direito. Florianópolis: Universidade Federal de Santa Catarina, 2010.

SPENGLER, Fabiana Marion. SPENGLER NETO, Theobaldo. Mediação enquanto política pública: o conflito, a crise da jurisdição e as práticas mediativas. Santa Cruz do Sul: UNISC, 2013.

SUARES, Marines. Mediación. Conducción de disputas, comunicación y técnicas. $1^{\circ}$ Ed. $8^{\circ}$ reimp. Buenos Aires: Paidós, 2012.

THE SCHOOL FOR CONFLICT ANALYSIS E RESOLUTION Commonwealth Center for Excellence. Disponível em http://scar.gmu.edu/people/sara-cobb. Acesso em 10.jan.14.

WARAT, Luis Alberto. Em nome do acordo. A mediação no Direito. Buenos Aires: Angra Impresiones, 1998. 